NASA/TM-2004-213389

\title{
Determination of Ground-Laboratory to In-Space Effective Atomic Oxygen Fluence for DC 93-500 Silicone
}

Kim K. de Groh and Bruce A. Banks

Glenn Research Center, Cleveland, Ohio

David Ma

Lockheed Martin Space Systems, Sunnyvale, California 
Since its founding, NASA has been dedicated to the advancement of aeronautics and space science. The NASA Scientific and Technical Information (STI) Program Office plays a key part in helping NASA maintain this important role.

The NASA STI Program Office is operated by Langley Research Center, the Lead Center for NASA's scientific and technical information. The NASA STI Program Office provides access to the NASA STI Database, the largest collection of aeronautical and space science STI in the world. The Program Office is also NASA's institutional mechanism for disseminating the results of its research and development activities. These results are published by NASA in the NASA STI Report Series, which includes the following report types:

- TECHNICAL PUBLICATION. Reports of completed research or a major significant phase of research that present the results of NASA programs and include extensive data or theoretical analysis. Includes compilations of significant scientific and technical data and information deemed to be of continuing reference value. NASA's counterpart of peerreviewed formal professional papers but has less stringent limitations on manuscript length and extent of graphic presentations.

- TECHNICAL MEMORANDUM. Scientific and technical findings that are preliminary or of specialized interest, e.g., quick release reports, working papers, and bibliographies that contain minimal annotation. Does not contain extensive analysis.

- CONTRACTOR REPORT. Scientific and technical findings by NASA-sponsored contractors and grantees.
- CONFERENCE PUBLICATION. Collected papers from scientific and technical conferences, symposia, seminars, or other meetings sponsored or cosponsored by NASA.

- SPECIAL PUBLICATION. Scientific, technical, or historical information from NASA programs, projects, and missions, often concerned with subjects having substantial public interest.

- TECHNICAL TRANSLATION. Englishlanguage translations of foreign scientific and technical material pertinent to NASA's mission.

Specialized services that complement the STI Program Office's diverse offerings include creating custom thesauri, building customized databases, organizing and publishing research results ... even providing videos.

For more information about the NASA STI Program Office, see the following:

- Access the NASA STI Program Home Page at http://www.sti.nasa.gov

- E-mail your question via the Internet to help@sti.nasa.gov

- Fax your question to the NASA Access Help Desk at 301-621-0134

- Telephone the NASA Access Help Desk at 301-621-0390

- Write to:

NASA Access Help Desk

NASA Center for AeroSpace Information 7121 Standard Drive

Hanover, MD 21076 
NASA/TM-2004-213389

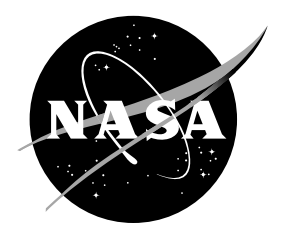

\section{Determination of Ground-Laboratory to In-Space Effective Atomic Oxygen Fluence for DC 93-500 Silicone}

Kim K. de Groh and Bruce A. Banks

Glenn Research Center, Cleveland, Ohio

David Ma

Lockheed Martin Space Systems, Sunnyvale, California

Prepared for the

Seventh International Conference on Protection of Materials and Structures From Space Environment cosponsored by the Materials Manufacturing Ontario and the Centre for Research in Earth and Space Technology (CRESTECH) Toronto, Canada, May 10-13, 2004

National Aeronautics and Space Administration

Glenn Research Center 


\section{Acknowledgments}

The authors would like to thank Phil Abel, NASA Glenn Research Center, for his consistent help with hardware set-up and introductions to the Park Scientific AFM and Hysitron systems. They also greatly appreciate all the many helpful insights and advice on calibration and testing procedures received from Lance Kuhn and Richard Nay, Hysitron.

Trade names or manufacturers' names are used in this report for identification only. This usage does not constitute an official endorsement, either expressed or implied, by the National Aeronautics and Space Administration.

Available from

NASA Center for Aerospace Information 7121 Standard Drive

Hanover, MD 21076
National Technical Information Service 5285 Port Royal Road Springfield, VA 22100 


\title{
Determination of Ground-Laboratory to In-Space Effective Atomic Oxygen Fluence for DC 93-500 Silicone
}

\author{
Kim K. de Groh and Bruce A. Banks \\ National Aeronautics and Space Administration \\ Glenn Research Center \\ Cleveland, Ohio 44135 \\ David Ma \\ Lockheed Martin Space Systems \\ Sunnyvale, California 94089
}

\begin{abstract}
SUMMARY
The objective of this research was to calibrate the ground-to-space effective atomic oxygen fluence for DC 93-500 silicone in a thermal energy electron cyclotron resonance (ECR) oxygen plasma facility. Silicones, commonly used spacecraft materials, do not chemically erode with atomic oxygen attack like other organic materials. Silicones react with atomic oxygen and form an oxidized hardened silicate surface layer. Therefore, the effective atomic oxygen fluence in a ground test facility should not be determined based on mass loss measurements, as they are with organic polymers, such as Kapton, a polyimide. A technique has been developed at the Glenn Research Center to determine the equivalent amount of atomic oxygen exposure in an ECR ground test facility to produce the same degree of atomic oxygen damage as in space. The approach used was to compare changes in the surface hardness of ground test (ECR) exposed DC 93-500 silicone with DC 93-500 exposed to low Earth orbit (LEO) atomic oxygen as part of a shuttle flight experiment. The ground to in-space effective atomic oxygen fluence correlation was determined based on the fluence in the ECR source that produced the same hardness for the fluence in-space. Because microhardness measurements need to be obtained on the very surface layer of a rubber substrate (with primarily elastic deformation) traditional techniques for microhardness that apply large forces and indentations based on plastic deformation, could not be used. Therefore, a nanomechanical measurement system operated in conjunction with an atomic force microscope (AFM) was used to determine the surface hardness of the silicones. The nanomechanical system can provide ultralight load indentations and can continuously measure force and displacement as an indent is made. Hardness versus contact depth measurements were obtained for five ECR exposed DC 93-500 samples (ECR exposed for 18 to $40 \mathrm{hrs}$, corresponding to Kapton effective fluences of $4.2 \times 10^{20}$ to $9.4 \times 10^{20}$ atoms $/ \mathrm{cm}^{2}$, respectively) and for space exposed DC 93-500 from the Evaluation of Oxygen Interactions with Materials III (EOIM III) shuttle flight experiment, exposed to LEO atomic oxygen for $2.3 \times 10^{20}$ atoms $/ \mathrm{cm}^{2}$. Pristine controls for the ECR tests and for the EOIM III flight sample were also evaluated. A ground-to-space correlation value was determined based on correlation values for four contact depths $(150,200,250$, and $300 \mathrm{~nm}$ ), which represent the near surface depth data. The results indicate that the Kapton effective atomic oxygen fluence in the ECR facility needs to be 2.64 times higher than in LEO to replicate equivalent exposure damage in the ground test silicone as occurred in the space exposed silicone.
\end{abstract}




\section{INTRODUCTION}

Silicones, a family of commonly used spacecraft materials, do not chemically erode away with atomic oxygen (AO) attack like other organic materials that have volatile oxidation products. Silicones react with $\mathrm{AO}$ and form an oxidized hardened silicate surface layer. Often loss of methyl groups causes shrinkage of the surface skin and "mud-tile" crazing degradation. But, silicones often do not lose mass, ${ }^{1}$ and some silicones actually gain mass during AO exposure. Therefore, the effective AO fluence for silicones in a ground-test facility should not be determined based on mass loss measurements, as they typically are with polymers such as Kapton. ${ }^{2}$ Another method for determining effective fluence needs to be employed.

A technique based on changes in surface hardness has been developed at the NASA Glenn Research Center. Specifically, this technique has been used to determine the equivalent amount of atomic oxygen oxidation via oxide hardness measurement. The approach was to compare changes in the surface hardness of ground-laboratory exposed DC 93-500 silicone with DC 93-500 exposed to LEO AO as part of a shuttle flight experiment. The ground to in-space effective atomic oxygen fluence was determined based on the Kapton effective fluence in the ground-laboratory facility that produced the same hardness for the fluence in-space. Because microhardness measurements need to be obtained on the very surface layer of a rubber substrate (with primarily elastic deformation) traditional techniques for microhardness characterization that apply relatively large forces and characterize hardness based on plastic deformation, could not be used. Therefore, nanomechanical testing using ultralight load indentations and continuous load-displacement monitoring was used to determine the surface hardness of the silicones. Hardness versus contact depth were obtained for five DC 93-500 samples exposed to AO in an electron cyclotron resonance (ECR) thermal energy source facility and for space exposed DC 93-500 from the Evaluation of Oxygen Interactions with Materials III (EOIM III) shuttle flight experiment. Ground-to-space correlation values were determined based on the near-surface depth data.

\section{EXPERIMENTAL PROCEDURES}

\subsection{Materials}

\subsubsection{93-500 Silicone}

The product name for DC 93-500 is Dow Corning ${ }^{\circledR}$ 93-500 Space Grade Encapsulant. It is supplied as a two-part liquid component kit. When the liquid components are thoroughly mixed, the mixture cures to a clear, flexible, low volatility space grade elastomer, which is suited for the protection of electrical/electronic assemblies, and has numerous other spacecraft applications. The service temperature range of DC $93-500$ is -45 to $200{ }^{\circ} \mathrm{C}\left(-49\right.$ to $\left.392{ }^{\circ} \mathrm{F}\right)$.

\subsubsection{Ground-Laboratory ECR AO Exposed DC 93-500}

The ground-laboratory test samples were exposed to AO in an ECR facility. These samples were approximately 0.25 by 0.25 in. $(0.635$ by $0.635 \mathrm{~cm})$ in size, and approximately 0.020 to 0.025 in. $(0.051$ to $0.064 \mathrm{~cm})$ thick. These samples were made to have the same thickness as the space flight sample, as thickness variations of soft materials could affect hardness values. All samples (pristine controls, ground-laboratory ECR exposed and the space flight sample) were mounted using the same type and thickness sample holder for hardness characterization. 


\subsubsection{In-Space Exposed DC 93-500}

The in-space exposed DC 93-500 sample was exposed to low Earth orbit (LEO) AO as part of the Evaluation of Oxygen Interactions with Materials III (EOIM III) shuttle flight experiment flown on STS-46. This sample was exposed to directed ram AO from within the shuttle bay and received a LEO atomic oxygen fluence of $2.3 \pm 0.3 \times 10^{20}$ atoms $/ \mathrm{cm}^{2}{ }^{3}$ The flight sample was $2.54 \mathrm{~cm}$ in diameter and was approximately 0.020 to $0.025 \mathrm{in}$. $(0.051$ to $0.064 \mathrm{~cm})$ thick. The silicone received enough AO while in LEO to cause significant micro-crazing of the surface. Pre- and post-flight micrographs of the flight sample surface are shown in Figure 1. A pristine control sample fabricated at the same time as the flight sample was also available for testing.

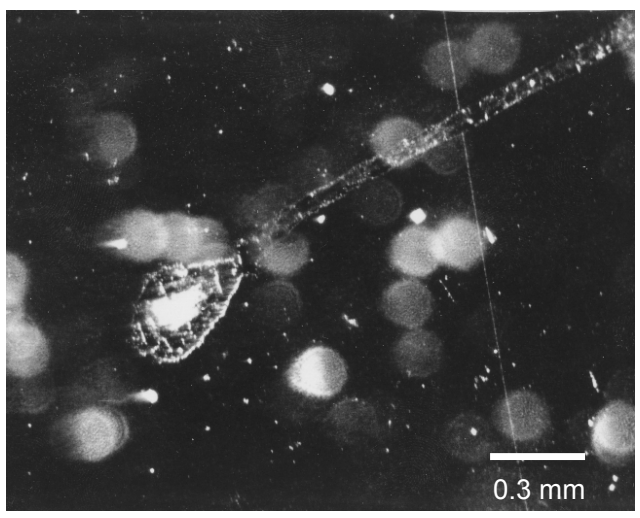

a.

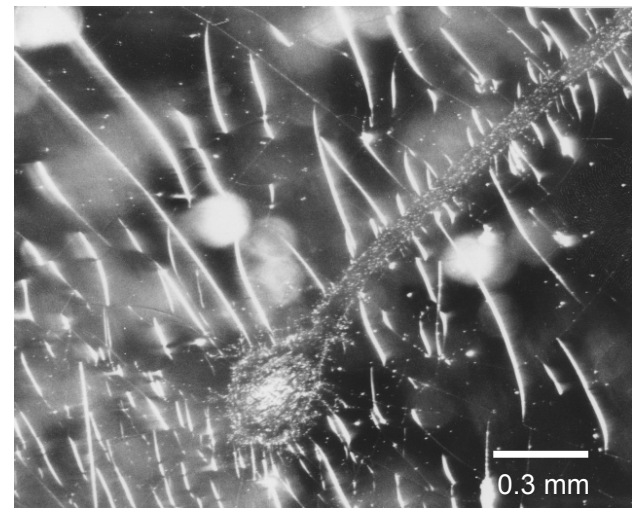

b.

Figure 1. Pre-flight and post-flight images of the EOIM III DC 93-500 sample: a) Pre-flight, and b) Post-flight showing surface crazing due to $\mathrm{AO}$ oxidation.

\subsection{Electron Cyclotron Resonance (ECR) Source AO Exposure}

The ground-laboratory test samples were exposed to AO in an electron cyclotron resonance (ECR) source facility at the Lockheed Martin Space System Company (LMSSC) Advanced Technology Center (ATC). This directional plasma system provides $\sim 90 \%$ thermal AO $(0.1 \mathrm{eV})$ and $\sim 10 \%$ ionized species $(15$ to $20 \mathrm{eV})$. The effective exposed area is 6 to $8 \mathrm{in}$. diameter with $\sim 20 \%$ drop-off at 4 in. off center. The Kapton effective atomic oxygen flux is $\sim 6 \times 10^{15}$ atoms $/ \mathrm{cm}^{2} \mathrm{sec}$ based on mass loss measurements. Five DC 93-500 samples were exposed to ECR AO from 18 to 40 hours. The sample temperature during ECR exposure was $80{ }^{\circ} \mathrm{C}$. The ground-laboratory exposed samples and the corresponding Kapton mass loss effective fluence values are provided in Table 1.

Table 1. ECR AO Exposed Samples.

\begin{tabular}{cc}
\hline $\begin{array}{c}\text { \# AO } \\
\text { Hours }\end{array}$ & $\begin{array}{c}\text { AO Kapton Effective Fluence } \\
\left(\times 10^{20} \text { atoms } / \mathrm{cm}^{2}\right)\end{array}$ \\
\hline 0 & 0 \\
\hline 18 & 4.2 \\
\hline 20 & 4.7 \\
\hline 24 & 5.6 \\
\hline 30 & 7.0 \\
\hline 40 & 9.4 \\
\hline
\end{tabular}




\subsection{Nanomechanical Hardness Testing}

\subsubsection{Nanoindentation Introduction}

The hardness of a material can be defined as the resistance to penetration, ${ }^{4}$ or the resistance to plastic deformation, and is dependent on the type of test used to determine its value. Traditional hardness testers force an indenter with known geometry into the surface of a material with a known applied load. Depending on the type of test, the hardness $(\mathrm{H})$ is expressed by a number that is either inversely proportional to the depth of indentation for a specified load and indenter, or equal to the load (P) over the area of indentation (A), $\mathrm{H}=\mathrm{P} / \mathrm{A} .^{5}$ It should be kept in mind that the hardness value obtained in a particular test serves only as a comparison between materials or treatments. ${ }^{5}$

Nanoindentation arose from the realization that an indentation test with a sharp indenter applied with a low force is an excellent way to measure very small volumes of materials and thin films. But, a need existed to be able to determine the indentation area without a high magnification microscope. Therefore, depth-sensing indentation (DSI) techniques were developed. Nanoindentation refers to depth-sensing indentation testing in the submicrometer range. In nanoindentation techniques, the load and displacement of the indenter are recorded during the indentation process and these data are analyzed to obtain the contact area, and thereby mechanical properties, without having to see the indentations. DSI techniques provide a means for studying elastic and time dependent plastic properties of materials.

In the TriboScope system, the procedure used to calculate the hardness $(\mathrm{H})$ from the loaddisplacement data is presented by Oliver and Pharr in reference 6, and is known as the Oliver and Pharr method. This method accounts for the curvature in the unloading data (nonlinear unloading) and uses a procedure for determining contact area (A) at peak load based on the indenter shape and depth of penetration. The hardness is defined as the mean pressure the material will support under load and is computed from the peak indentation load $\left(\mathrm{P}_{\max }\right)$ and the projected area of contact at peak load, $\mathrm{H}=\mathrm{P}_{\max } / \mathrm{A}^{6}{ }^{6}$ This hardness is different from the conventional definition of hardness because the nanomechanical hardness is calculated utilizing the contact area at maximum load whereas in conventional tests the area of the residual indent after unloading is used.

\subsubsection{TriboScope Nanomechanical Test System}

A Hysitron Inc. TriboScope ${ }^{\circledR}$ Nanomechanical Test System operated in conjunction with a Park Scientific AutoProbe atomic force microscope (AFM) was used to determine the surface hardness of the silicone samples. The TriboScope ${ }^{\circledR}$ nanomechanical test instrument is a quantitative depth-sensing nanoindentation system that uses a three-plate capacitive force/displacement transducer. The Hysitron nanomechanical system can provide ultralight load indentations (less than $25 \mu \mathrm{N}$ ) and continuously measures force and displacement as an indent is made. It should be noted that the maximum force experienced by these samples (the sample force, $\mathrm{F}_{\text {sample }}$ ) is not the same as the prescribed applied force (the force applied to the center plate of the transducer, $\mathrm{F}_{\text {applied }}$ ), primarily due to the large displacement of these samples with soft substrates.

\subsubsection{Indentation Procedures}

The transducer tip was brought into contact with the surface of the sample using the AFM electronics and feedback system. Once in contact with the surface the tip was left at an ultralight pre-load and the system was left to settle for two minutes prior to starting the indent, to minimize drift. Indentations in the test samples were taken using a trapezoid loading curve with a 20 second hold period ( 5 second ramp up, 
20 second hold, 5 second ramp down) using a Berkovich indenter. A Berkovich tip is a three-sided pyramid tip with an area-to-depth function which is the same as that of a Vickers indenter. ${ }^{7}$ The total included angle of a Berkovich tip is $142.3^{\circ}$ with a half angle of $65.35^{\circ}$. This tip geometry has been used as the standard for nanoindentation. The average radius of curvature is typically between 100 and $200 \mathrm{~nm}$. Indents were made with applied forces ranging from 75 to $900 \mu \mathrm{N}$, and up to $1500 \mu \mathrm{N}$ when possible. The maximum applied load was determined by the limit of the transducer displacement for each sample $(\approx 4700 \mathrm{~nm})$. Each indentation was taken at a new sample location. Approximately 20 to 25 individual indentations were obtained for each sample. Pre-loads of $0.112 \mathrm{mg}(1.10 \mu \mathrm{N})$ were used for less than 200 $\mu \mathrm{N}$ applied indent force indents. Pre-loads of $0.125 \mathrm{mg}(1.23 \mu \mathrm{N})$ were typically used for higher than 200 $\mu \mathrm{N}$ load forces. In some of the earlier test sets pre-loads of $0.111 \mathrm{mg}(1.09 \mu \mathrm{N})$ were used for higher forces, but were determined not to affect the hardness values for the higher loads.

\section{RESULTS AND DISCUSSION}

\subsection{Pristine DC 93-500 (ECR Control)}

During indent testing of the pristine DC 93-500, negative unloading force values were observed in the real time force versus displacement data during the second set of indents, possibly indicating tip contamination. Tests were conducted that verified that the sample tip was contaminated from the silicone (i.e. repeated indents were consistently "softer" than the original data taken at the same location prior to tip contamination). After tip cleaning, additional data was taken to verify that the tip was not changed. The results of the non-contaminated pristine data obtained during two separate indent sessions at two different locations are provided in Figure 2 along with a curve fit for the data. An image of the sample surface is also provided in Figure 2. As can be seen, the hardness of the pristine silicone is greater at the near surface than deeper in the bulk of the material. This is commonly found for both metal and polymer materials using nanoindentation techniques. Polymers typically display greater hardness values at the surface because of air or light induced cross-linking and ambient oxidation of the sample.

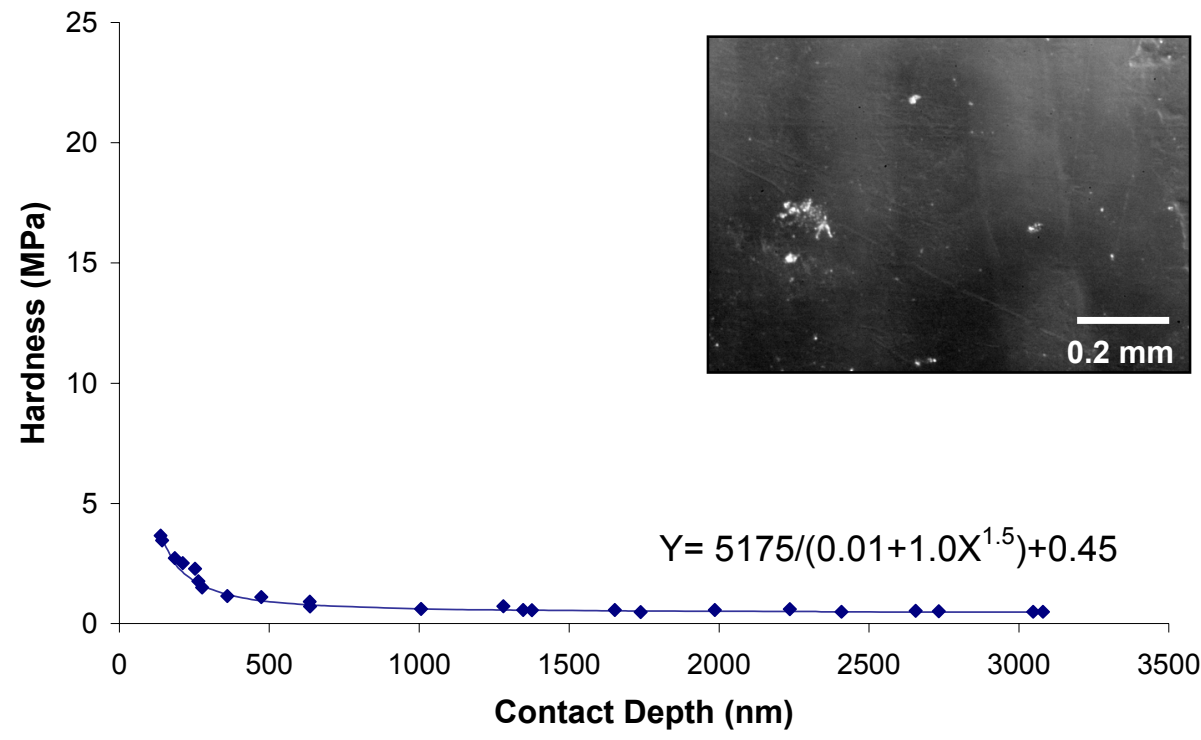

Figure 2. Hardness versus contact depth for the pristine DC 93-500 ECR control sample. 


\subsection{Hour AO exposed DC 93-500}

The 18 hour ECR exposed sample received a Kapton effective fluence of $4.2 \times 10^{20}$ atoms $/ \mathrm{cm}^{2}$. Hardness data was acquired on the 18 hour AO exposed sample during two indentation sessions at different locations. The hardness versus contact depth data is provided in Figure 3 along with a curve fit for the data. An image of the sample surface is also provided in Figure 3 and shows that very fine microcracks have developed.

An interesting effect was observed in the 18 hour sample data at higher applied indent forces $(400,600,800$, and $900 \mu \mathrm{N})$. An apparent "film break-through" was displayed in the loading curve. It appears that the tip was broken through a hardened surface layer and down into a softer underlying layer. An example is provided in Figure 4 for the $900 \mu \mathrm{N}$ applied force indent in the 18 hour AO exposed sample. This type of break-through was observed for most of the oxidized films after some loading force is applied. It should be noted that the screen image shown in Figure 4, provides the displacement at breakthrough, not the actual contact depth.

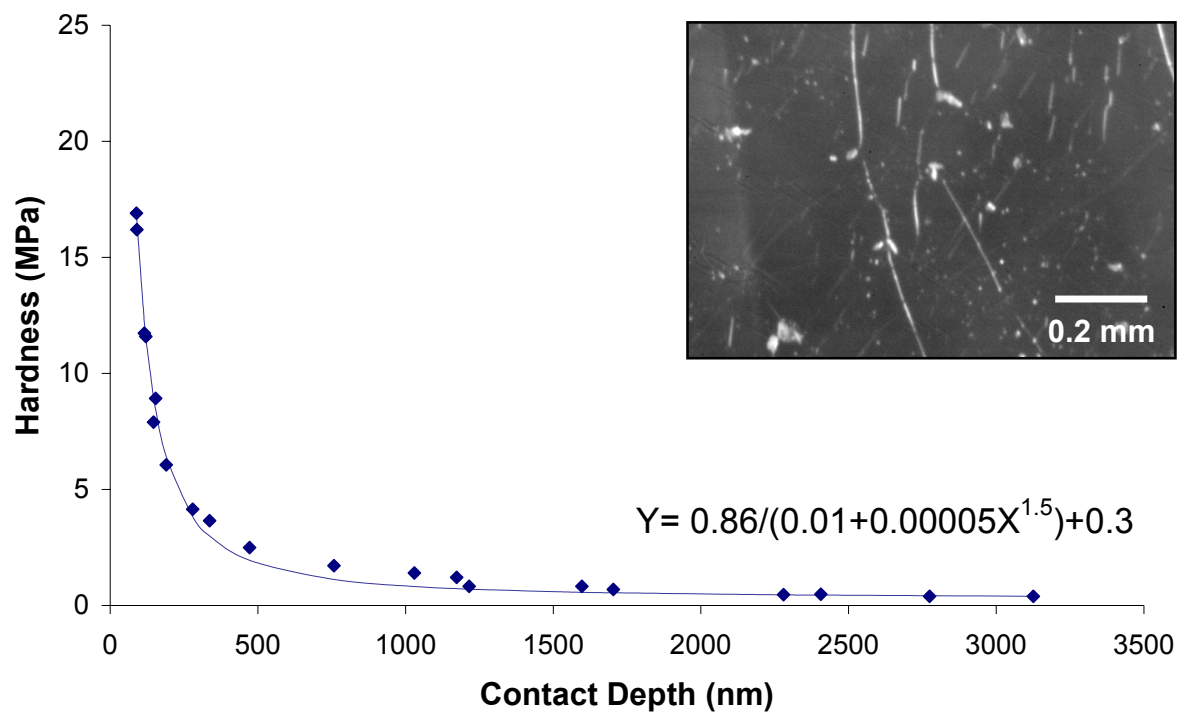

Figure 3. Hardness versus contact depth for the 18 hour ECR AO exposed DC 93-500.

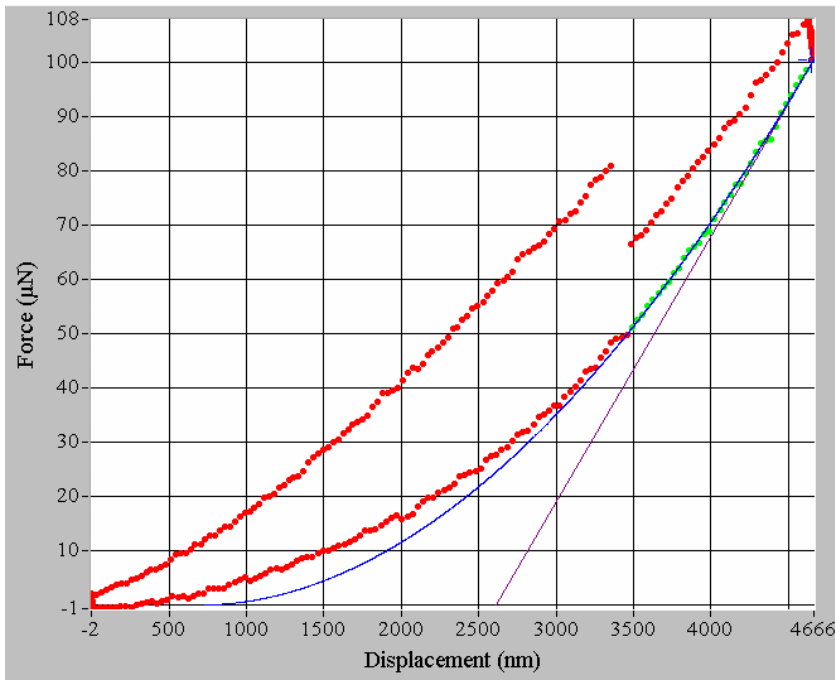

Figure 4. TriboScope software sample force versus displacement curve for $900 \mu \mathrm{N}$ applied force indent in the 18 hour AO exposed DC 93-500 sample. 


\subsection{Hour AO Exposed DC 93-500}

The 20 hour ECR exposed sample received a Kapton effective fluence of $4.7 \times 10^{20}$ atoms $/ \mathrm{cm}^{2}$. Hardness data was acquired on the 20 hour AO exposed sample during two separate indentation sessions at two different locations. The hardness versus contact depth data is provided in Figure 5 along with a curve fit for the data. There was a fair amount of scatter in the data for contact depths between approximately 200 to $500 \mathrm{~nm}$. Film break-through was observed when using the 500, 700, and $800 \mu \mathrm{N}$ applied indent forces. An image of the sample surface is also provided in Figure 5 and shows that the surface has finer craze line than the 18 hour exposed sample.

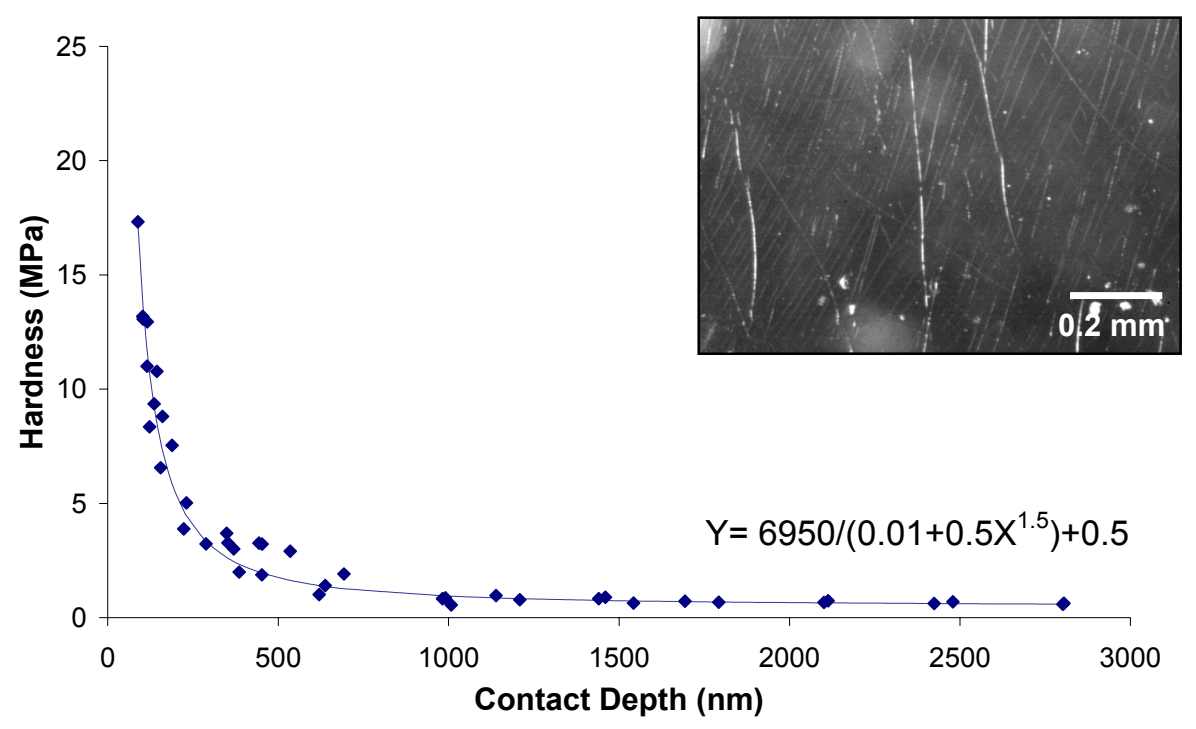

Figure 5. Hardness versus contact depth for the 20 hour ECR AO exposed DC 93-500. 


\subsection{Hour AO Exposed DC 93-500}

The 24 hour ECR exposed sample received a Kapton effective fluence of $5.6 \times 10^{20}$ atoms $/ \mathrm{cm}^{2}$. The 24 hour sample was indented during one session at two different regions. The hardness versus contact depth data is provided in Figure 6 along with a curve fit for the data. Film break-through was observed for all indents at or above $200 \mu \mathrm{N}$ applied indent forces. An image of the sample surface is also provided in Figure 6 and shows that the surface has a well developed crazed texture.

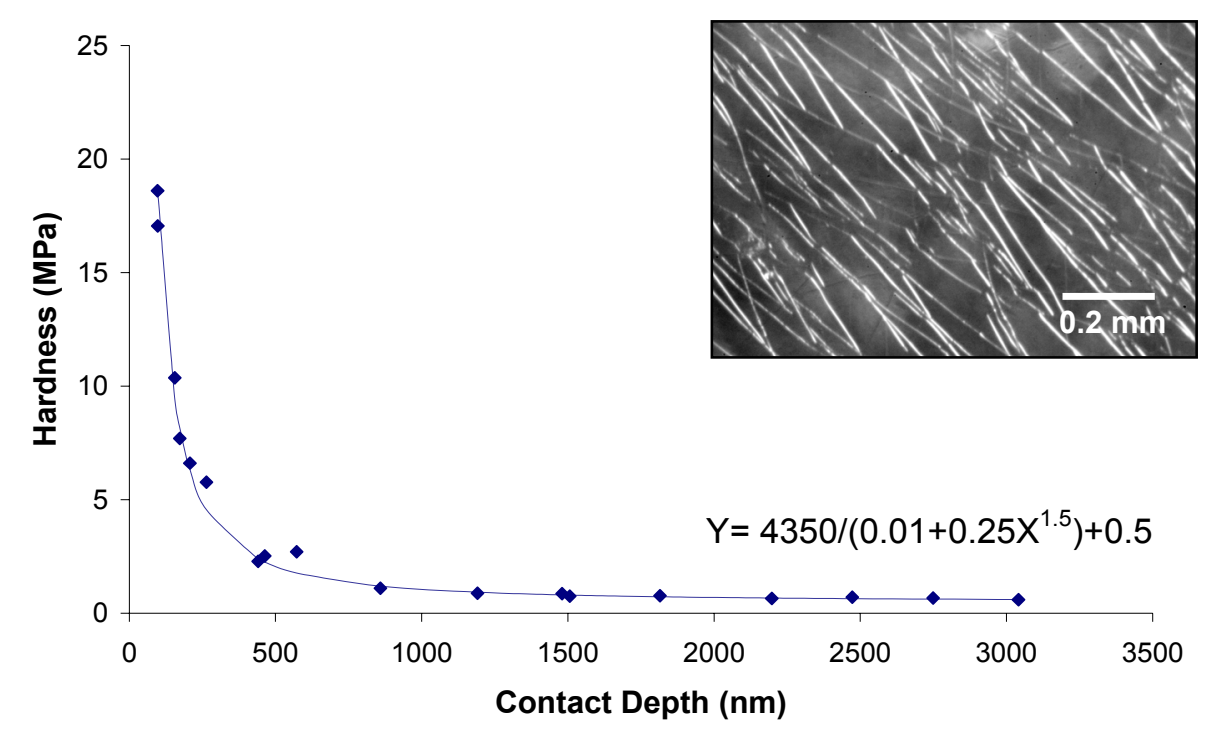

Figure 6. Hardness versus contact depth for the 24 hour ECR AO exposed DC 93-500. 


\subsection{Hour AO Exposed DC 93-500}

The 30 hour ECR exposed sample received a Kapton effective fluence of $7.0 \times 10^{20}$ atoms $/ \mathrm{cm}^{2}$. The hardness versus contact depth data is provided in Figure 7 along with a curve fit for the data. Film breakthrough was observed for all indents at or above $300 \mu \mathrm{N}$ applied indent forces. An image of the sample surface is also provided in Figure 7 and shows that the surface has a well developed crazed texture like the 24 hour exposed sample.

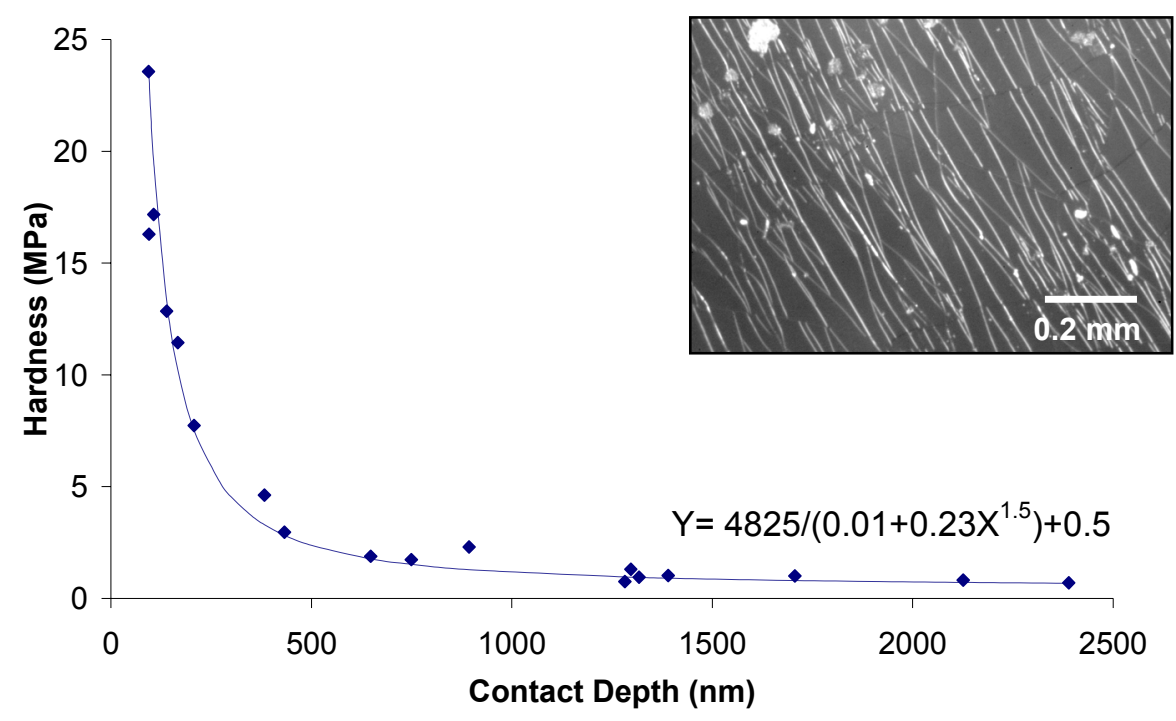

Figure 7. Hardness versus contact depth for the 30 hour ECR AO exposed DC 93-500. 


\subsection{Hour AO Exposed DC 93-500}

The 40 hour ECR exposed sample received a Kapton effective fluence of $9.4 \times 10^{20}$ atoms $/ \mathrm{cm}^{2}$. The hardness versus contact depth data was obtained at two separate regions of the sample. The hardness versus contact depth data is provided in Figure 8 along with a curve fit for the data. Film break-through was observed for indents at or above $625 \mu \mathrm{N}$ applied indent forces. An image of the sample surface is also provided in Figure 8 and like the 24 and 30 hour exposed samples, shows a well developed crazed texture.

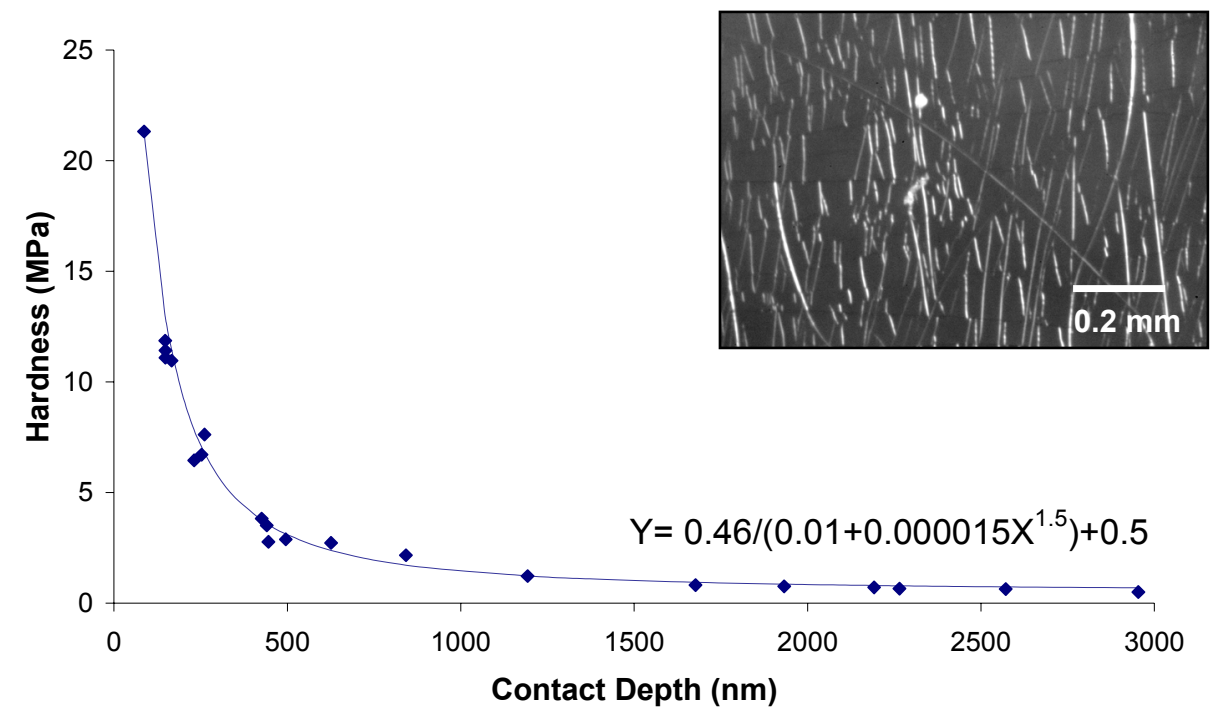

Figure 8. Hardness versus contact depth for the 40 hour ECR AO exposed DC 93-500. 


\subsection{EOIM III Control DC 93-500}

The hardness versus contact depth data for the EOIM III control sample is provided in Figure 9 along with a curve fit for the data.

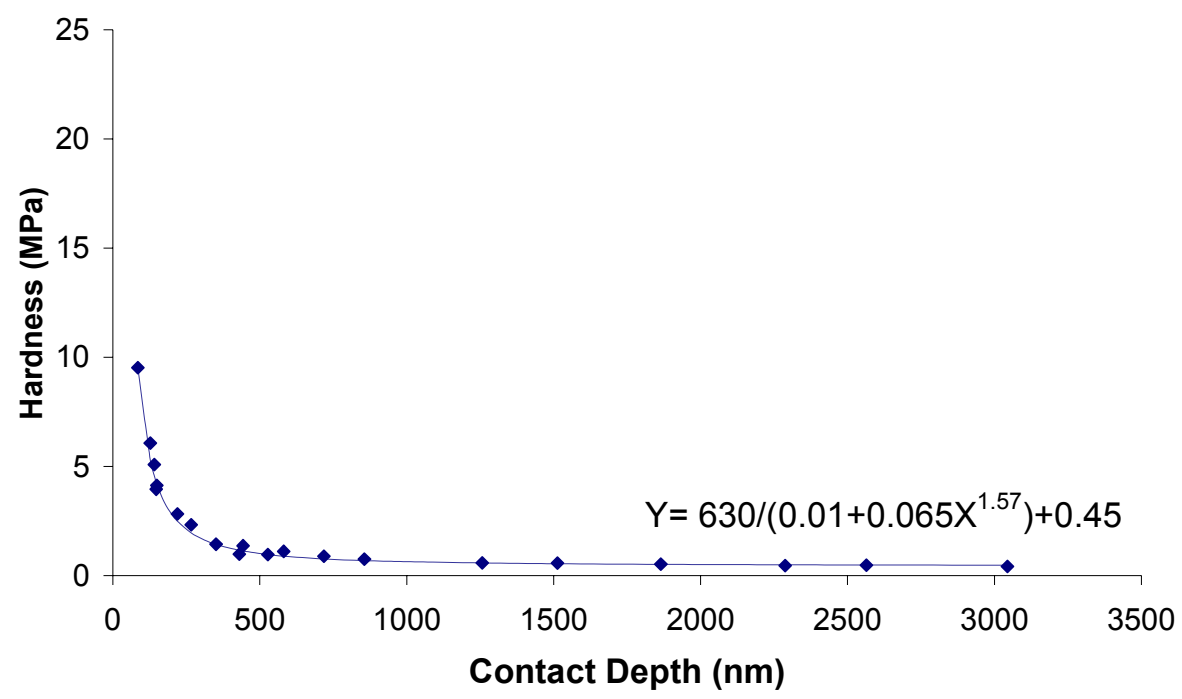

Figure 9. Hardness versus contact depth for the EOIM III control sample fabricated at the same time as the flight sample.

\subsection{EOIM III DC 93-500 Flight Sample}

The EOIM III flight sample was exposed to a LEO AO fluence of $2.3 \times 10^{20}$ atoms $/ \mathrm{cm}^{2}$. The hardness versus contact depth data is provided in Figure 10 along with a curve fit for the data. Film break-through was observed for indents at 600 and $700 \mu \mathrm{N}$ applied indent forces. An image of the sample surface is also provided in Figure 10 and shows that the surface has a well-developed crazed texture.

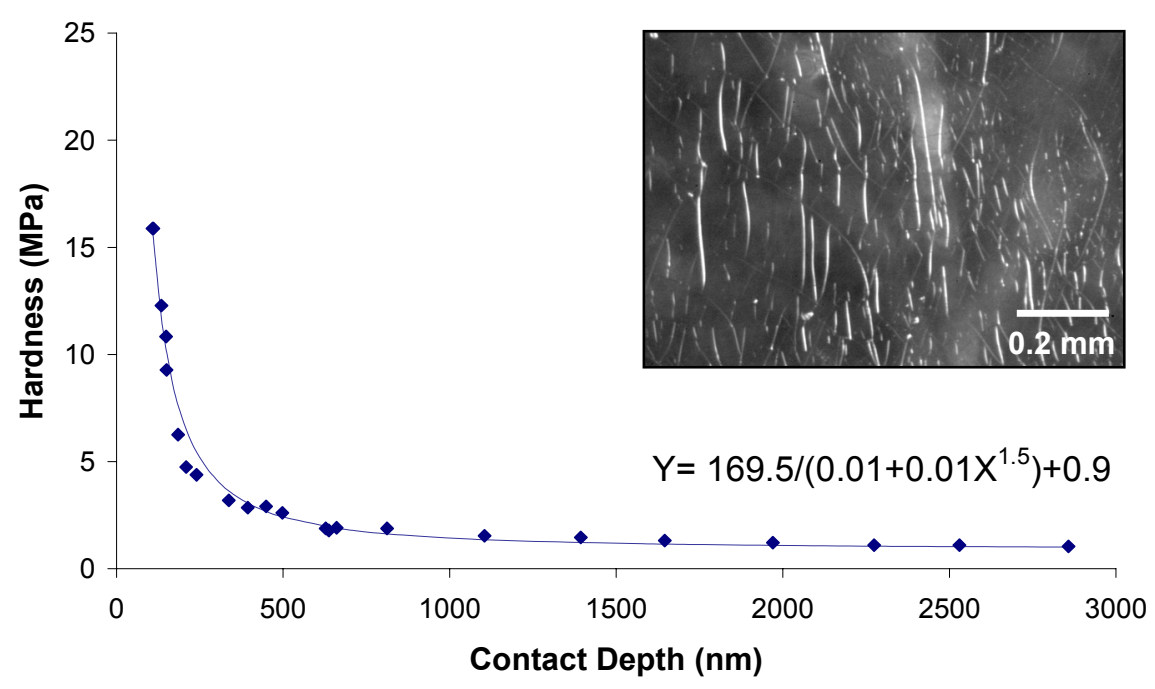

Figure 10. Hardness versus contact depth for the EOIM III flight sample. 


\subsection{Ground-Laboratory to In-Space Effective Fluence for the ECR Facility}

The AO exposure does cause surface hardening, as expected, as the silicone is oxidized. The nanomechanical hardness data indicate that the AO exposed samples are substantially harder at the near surface than the pristine silicone. Another observation is that the hardened layer decreases with depth, as one would expect, with the hardness of the AO exposed samples becoming the same as pristine DC 93-500 at a depth of approximately $1500 \mathrm{~nm}$. The consistency of the hardness for all samples below this depth was excellent, and shows excellent repeatability of this nanomechanical technique. There was a fair amount of scatter and data overlap for some samples at the low applied indent forces. Surface roughness, such as that which occurs with the "mud-tile" cracking of the oxidized silicate layer, and inhomogeneities in the surface oxide could contribute to hardness variations, particular for low force indents.

Although film break-through was observed at various applied loads for all oxidized films (e.g. the ECR and flight samples), specific trends were not investigated. This would require additional analyses of the force versus distance curves to determine the specific depth of contact and applied load for which break-through occurred. This information was not readily available. As previously mentioned, the observation of film break-through confirms that an embrittled oxidized layer has developed over the soft underlying silicone layer.

Using values obtained from the curve fit equations for each data set (the curve fit equations are given in the hardness vs. depth charts); plots of hardness versus Kapton effective fluence at contact depths of 150, 200, 250, and $300 \mathrm{~nm}$ were produced. These depths represent the "near surface" data. The $150 \mathrm{~nm}$ contact depth and $300 \mathrm{~nm}$ contact depth plots are provided in Figure 11a and 11b, respectively. The hardness for the ECR pristine sample and the EOIM III control samples were very similar. The EOIM III control was slightly harder at a contact depth of $150 \mathrm{~nm}$, which is not surprising. Even if the mix ratios and degrees of cure were the same for both controls, because the EOIM III control was made years earlier there would be a difference in the quantity of residual outgassing products and oxidation that could increase the hardness slightly over time. These aging differences may also affect the flight sample hardness, but are considered negligible, as the hardness difference of the two controls was determined to be insignificant at a contact depth of $150 \mathrm{~nm}$ (and they were essentially the same at $300 \mathrm{~nm}$ ).

Based on the linear fits for the hardness versus exposure time data, the ECR Kapton effective fluence that provided the same hardness as the EOIM III sample for 150, 200, 250, and $350 \mathrm{~nm}$ depth was 6.10, $6.00,6.04$, and $6.16 \times 10^{20}$ atoms $/ \mathrm{cm}^{2}$, respectively. Averaging these values provides $6.08 \times 10^{20}$ atoms $/ \mathrm{cm}^{2}$, therefore the Kapton effective atomic oxygen fluence in the ECR facility needs to be 2.64 times higher than in LEO to replicate equivalent exposure damage in the ground test silicone as occurred in the space exposed silicone.

When comparing the surface crazing, the extent of crazing in the 18 and 20 hour ECR exposed samples appears to be less developed than the flight sample, while the 24 hour ECR exposed sample seems more substantially crazed like the flight sample. This is a qualitative assessment only, and may be contributed to through sample handling procedures. For comparison purposes, the hardness versus contact depth curves for the EOIM III flight sample and the 24 hour ECR sample, which was closest for the necessary ECR fluence for equivalent damage, were overlaid along with the pristine ECR sample data and are provided in Figure 12. 
It should be noted that consistency in the sample thickness, sample holder and nanoindentation technique for obtaining nanomechanical hardness data is very important. This is particularly true when the hardness changes substantially with depth such as with these samples. It is believed that these results will apply to chemically similar silicones in thermal energy AO systems. Further testing should be conducted to verify this. Similar tests should be conducted to get a ground-laboratory to in-space effective fluence correlation for silicones in higher energy AO facilities.

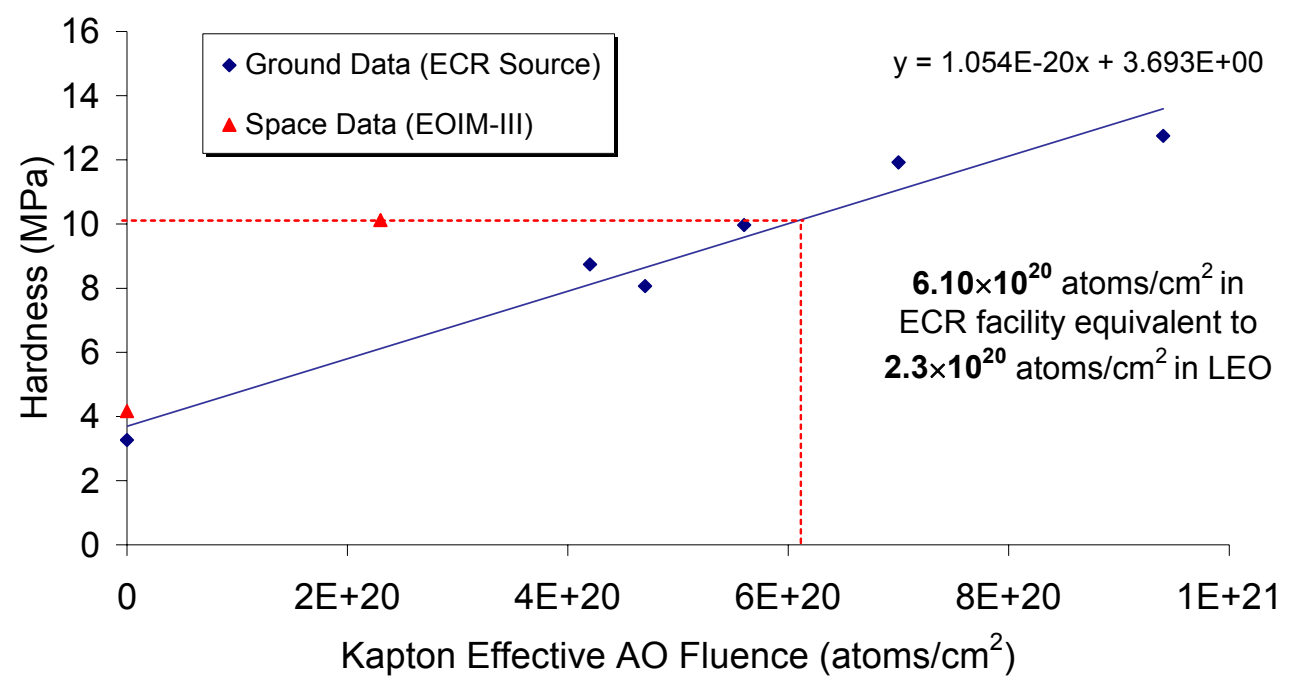

a.

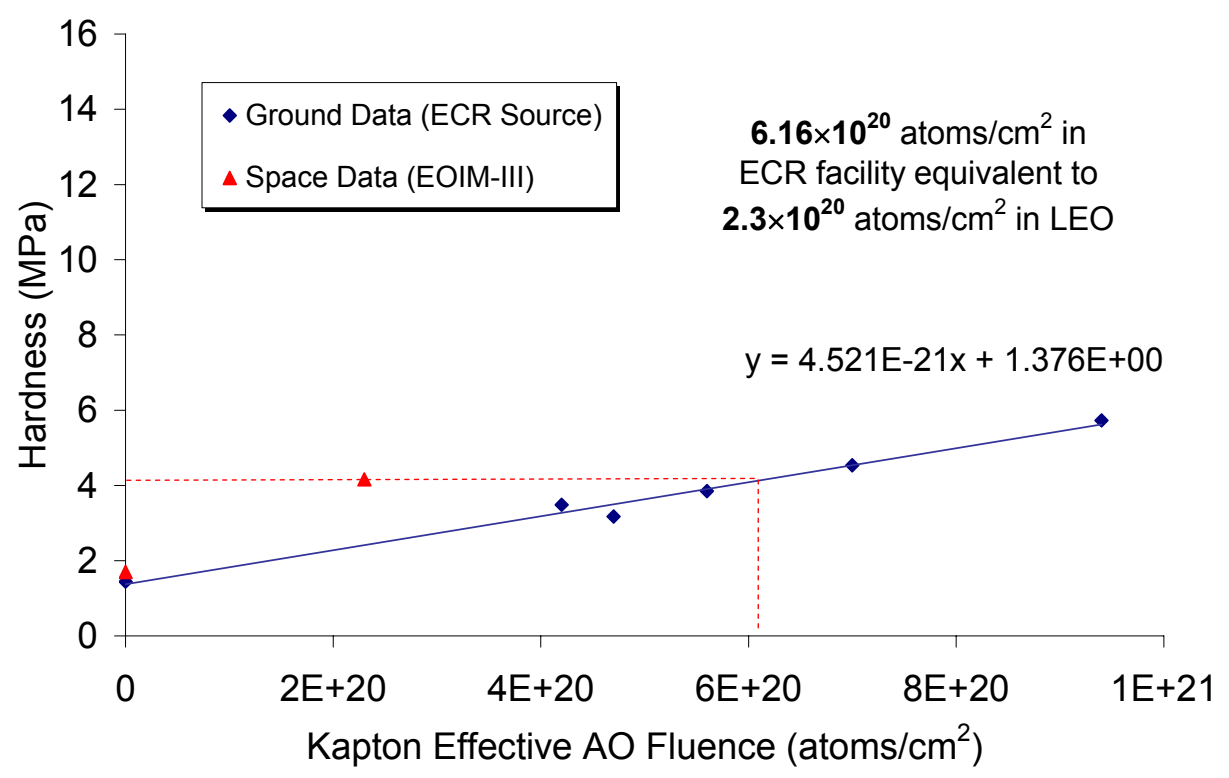

b.

Figure 11. Hardness versus Kapton Effective AO effective fluence: a) at a contact depth of $150 \mathrm{~nm}$, and b) at a contact depth of $300 \mathrm{~nm}$. 


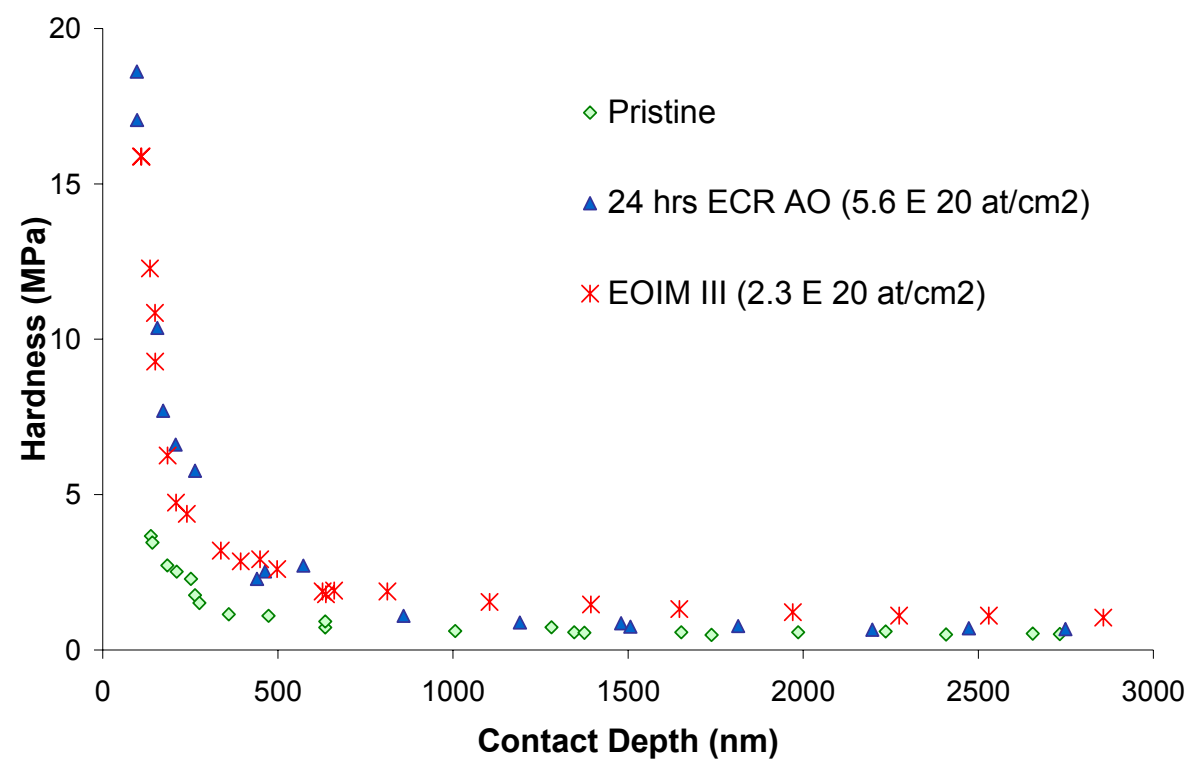

Figure 12. Hardness versus contact depth for pristine, 24 hour ECR exposed and LEO space exposed DC 93-500 silicone.

\section{RELEVANCE TO ISS}

This method is relevant to silicone pressure sensitive adhesive (PSA) samples that were ECR exposed for International Space Station (ISS) solar array diode tape blocking assessment. The DC 93-500 samples as described herein were ECR exposed simultaneously with silicone PSA samples. On-orbit, the silicone PSA surface will eventually convert to a hardened silicate glass layer, converting a sticky surface to a glassy non-block surface. By using the correlation of ground and space DC 93-500 data, the ground test effective fluence of the silicone PSA can be deduced and the degree of blocking versus AO exposure that can be expected on-orbit for the ISS diode tape can be more accurately determined.

\section{SUMMARY AND CONCLUSIONS}

Traditional techniques for determining effective AO fluence exposures in ground-laboratory facilities based on mass loss measurements should not be used for silicones. Therefore, a technique has been developed for ground-laboratory to in-space effective AO fluence determination for silicones based on changes in surface hardness, which occurs as the silicone is oxidized. Specifically, nanoindentation hardness measurements were determined for ground test (ECR) exposed DC 93-500 silicone and DC 93-500 exposed to LEO AO as part of the EOIM III shuttle flight experiment. The ground to in-space effective AO fluence was determined based on the Kapton effective fluence in the ECR source that produced the same hardness for the fluence in-space. Preliminary calibration and optimization testing of the nanomechanical system with silicone samples were conducted and critical issues reviewed. Hardness versus contact depth measurements were obtained for five ECR exposed DC 93-500 samples (ECR exposed for 18 to $40 \mathrm{hrs}$, corresponding to Kapton mass loss effective fluences of $4.2 \times 10^{20}$ to $9.4 \times 10^{20}$ atoms $/ \mathrm{cm}^{2}$, respectively) and for the EOIM III LEO exposed DC 93-500 silicone. Pristine controls for the 
ECR tests and for the EOIM III flight sample were also measured. The ground-to-space correlation value was determined based on correlation values for four contact depths $(150,200,250$, and $300 \mathrm{~nm}$ ), which represent the "near surface" depth data. The results indicate that the Kapton effective AO fluence in the ECR facility needs to be 2.64 times higher than in LEO to replicate equivalent exposure damage in the ground test silicone as occurred in the space exposed silicone.

\section{REFERENCES}

1. C. Hung and G Cantrell, "Reaction and Protective of Electrical Wire Insulators in Atomic-Oxygen Environment," NASA TM-106767, 1994.

2. ASTM E 2089-00, "Standard Practices for Ground Laboratory Atomic Oxygen Interaction Evaluation of Materials for Space Applications," June 2000.

3. S.L. Knootz, L.J. Leger, S.L. Rickman, C.L. Hakes, D.T. Bui, D.E. Hunton, and J.B. Cross, J. of Spacecraft and Rockets, Vol. 32, No. 3, 1995, 475-482.

4. R.E. Smallman, Modern Physical Metallurgy, Butterworths \& Co (Publishers) Ltd, England 1985.

5. S.H. Avner, Introduction to Physical Metallurgy, 2nd Ed., McGraw-Hill, Inc. 1974.

6. W.C. Oliver and G.M. Pharr, J. Mater. Res., Vol. 7, No. 6, 1992, 1564-1583. 
Public reporting burden for this collection of information is estimated to average 1 hour per response, including the time for reviewing instructions, searching existing data sources, gathering and maintaining the data needed, and completing and reviewing the collection of information. Send comments regarding this burden estimate or any other aspect of this collection of information, including suggestions for reducing this burden, to Washington Headquarters Services, Directorate for Information Operations and Reports, 1215 Jefferson Davis Highway, Suite 1204, Arlington, VA 22202-4302, and to the Office of Management and Budget, Paperwork Reduction Project (0704-0188), Washington, DC 20503.

\begin{tabular}{|l|l|l|}
\hline 1. AGENCY USE ONLY (Leave blank) & $\begin{array}{c}\text { 2. REPORT DATE } \\
\text { December } 2004\end{array}$ & $\begin{array}{r}\text { 3. REPORT TYPE AND DATES COVERED } \\
\text { Technical Memorandum }\end{array}$ \\
\hline
\end{tabular}

\section{TITLE AND SUBTITLE}

Determination of Ground-Laboratory to In-Space Effective Atomic Oxygen

Fluence for DC 93-500 Silicone

\section{6. $\operatorname{AUTHOR(S)}$}

Kim K. de Groh, Bruce A. Banks, and David Ma

\section{FUNDING NUMBERS}

WBS-22-319-20-E1

\section{PERFORMING ORGANIZATION NAME(S) AND ADDRESS(ES)}

National Aeronautics and Space Administration

John H. Glenn Research Center at Lewis Field

Cleveland, Ohio 44135-3191
8. PERFORMING ORGANIZATION REPORT NUMBER

E-14897

\section{SPONSORING/MONITORING AGENCY NAME(S) AND ADDRESS(ES)}

10. SPONSORING/MONITORING AGENCY REPORT NUMBER

NASA TM-2004-213389

\section{SUPPLEMENTARY NOTES}

Prepared for the Seventh International Conference on Protection of Materials and Structures From Space Environment cosponsored by the Materials Manufacturing Ontario and the Centre for Research in Earth and Space Technology (CRESTECH), Toronto, Canada, May 10-13, 2004. Kim K. de Groh and Bruce A. Banks, NASA Glenn Research Center; and David Ma, Lockheed Martin Space Systems, Sunnyvale, California 94089. Responsible person,

Kim K. de Groh, organization code 5480, 216-433-2297.

12a. DISTRIBUTION/AVAILABILITY STATEMENT

12b. DISTRIBUTION CODE

Unclassified - Unlimited

Subject Category: 18 and 27

Distribution: Nonstandard

Available electronically at http://gltrs.grc.nasa.gov

This publication is available from the NASA Center for AeroSpace Information, 301-621-0390.

\section{ABSTRACT (Maximum 200 words)}

The objective of this research was to calibrate the ground-to-space effective atomic oxygen fluence for DC 93-500 silicone in a thermal energy electron cyclotron resonance (ECR) oxygen plasma facility. Silicones, commonly used spacecraft materials, do not chemically erode with atomic oxygen attack like other organic materials but form an oxidized hardened silicate surface layer. Therefore, the effective atomic oxygen fluence in a ground test facility should not be determined based on mass loss measurements, as they are with organic polymers. A technique has been developed at the Glenn Research Center to determine the equivalent amount of atomic oxygen exposure in an ECR ground test facility to produce the same degree of atomic oxygen damage as in space. The approach used was to compare changes in the surface hardness of ground test (ECR) exposed DC 93-500 silicone with DC 93-500 exposed to low Earth orbit (LEO) atomic oxygen as part of a shuttle flight experiment. The ground to in-space effective atomic oxygen fluence correlation was determined based on the fluence in the ECR source that produced the same hardness for the fluence in-space. Nanomechanical hardness versus contact depth measurements were obtained for five ECR exposed DC 93-500 samples (ECR exposed for 18 to 40 hrs, corresponding to Kapton effective fluences of $4.2 \times 10^{20}$ to $9.4 \times 10^{20}$ atoms $/ \mathrm{cm}^{2}$, respectively) and for space exposed DC 93-500 from the Evaluation of Oxygen Interactions with Materials III (EOIM III) shuttle flight experiment, exposed to LEO atomic oxygen for $2.3 \times 10^{20}$ atoms $/ \mathrm{cm}^{2}$. Pristine controls were also evaluated. A ground-to-space correlation value was determined based on correlation values for four contact depths (150, 200, 250, and 300 nm), which represent the near surface depth data. The results indicate that the Kapton effective atomic oxygen fluence in the ECR facility needs to be 2.64 times higher than in LEO to replicate equivalent exposure damage in the ground test silicone as occurred in the space exposed silicone.

\section{SUBJECT TERMS}

Silicone; Atomic Oxygen; Fluence; Space environment; Environment effects; Space flight experiment; Hardness; Indentation; Ground tests; Environmental durability; Low Earth orbit; Oxidation; Nanomechanical hardness; Calibration

\section{SECURITY CLASSIFICATION OF REPORT \\ Unclassified \\ 18. SECURITY CLASSIFICATION OF THIS PAGE \\ Unclassified}

19. SECURITY CLASSIFICATION OF ABSTRACT

Unclassified
15. NUMBER OF PAGES

21

16. PRICE CODE

\section{LIMITATION OF ABSTRACT}

Standard Form 298 (Rev. 2-89)

Prescribed by ANSI Std. Z39-18 298-102 

